\title{
The Influence of Maternal Body Mass Index on Infant Adiposity and Hepatic Lipid Content
}

\author{
NEENA MODI, DOMINIKA MURGASOVA, RIKKE RUAGER-MARTIN, E. LOUISE THOMAS, MATTHEW J. HYDE, \\ CHRISTOPHER GALE, SHALINI SANTHAKUMARAN, CAROLINE J. DORÉ, AFSHIN ALAVI, AND JIMMY D. BELL
}

\author{
Department of Medicine [N.M., D.M., R.R.-M., M.J.H., C.G., S.S.], Imperial College London, London SW10 9NH; Metabolic and \\ Molecular Imaging Group [E.L.T., J.D.B.], Imperial College London, London W12 ONN; Medical Research Council Clinical Trials Unit \\ [C.J.D.], London NW1 2DA; Radiology Department [A.A.], St Mary's Hospital, London W2 1NY, United Kingdom
}

\begin{abstract}
Maternal overweight and obesity are associated with adverse offspring outcome in later life. The causal biological effectors are uncertain. Postulating that initiating events may be alterations to infant body composition established in utero, we tested the hypothesis that neonatal adipose tissue (AT) content and distribution and liver lipid are influenced by maternal BMI. We studied 105 healthy mother-neonate pairs. We assessed infant AT compartments by whole body MR imaging and intrahepatocellular lipid content by ${ }^{1} \mathrm{H}$ MR spectroscopy. Maternal BMI ranged from 16.7 to 36.0. With each unit increase in maternal BMI, having adjusted for infant sex and weight, there was an increase in infant total $(8 \mathrm{~mL} ; 95 \% \mathrm{CI}$, $0.09-14.0 ; p=0.03)$, abdominal $(2 \mathrm{~mL} ; 95 \% \mathrm{CI}, 0.7-4.0 ; p=$ $0.005)$, and nonabdominal $(5 \mathrm{~mL} ; 95 \% \mathrm{CI}, 0.09-11.0 ; p=0.054)$ AT, and having adjusted for infant sex and postnatal age, an increase of $8.6 \%$ (95\% CI, 1.1-16.8; $p=0.03)$ in intrahepatocellular lipid. Infant abdominal AT and liver lipid increase with increasing maternal BMI across the normal range. These effects may be the initiating determinants of a life-long trajectory leading to adverse metabolic health. (Pediatr Res 70: 287-291, 2011)
\end{abstract}

$\mathrm{O}^{\prime}$ besity in women of childbearing age in the United Kingdom increased from $12 \%$ in 1993 to $18.5 \%$ in 2006 (1). There is every indication of continuing increase, in keeping with a shift to the right of the population distribution curve for maternal BMI. Overweight and obesity in infancy and childhood are also increasing, as are the features of the metabolic syndrome in the pediatric population (2). The hazards of maternal overweight and obesity to mother and baby, documented in the UK Confidential Enquiry into Maternal and Child Health report "Why Mothers Die" (3), show that mothers are at greater risk of miscarriage, high blood pressure, gestational diabetes, and Caesarean section. Infant outcomes are reflected in increased perinatal mortality and short-term morbidity, and in childhood, increased risk of features of the metabolic syndrome $(4,5)$ and doubling in the risk of obesity (6). Babies are further disadvantaged as overweight/obese mothers are less able to initiate and maintain breastfeeding $(7,8)$ although whether this contributes to the greater risk of obesity in later life is uncertain (9).

Received November 29, 2010; accepted March 12, 2011.

Correspondence: Neena Modi, M.D., Department of Medicine, Section of Neonatal Medicine, Imperial College London, Chelsea \& Westminster Hospital Campus, 369 Fulham Road, London SW10 9NH, United Kingdom; e-mail: n.modi@imperial.ac.uk

Supported by the Medical Research Council and Chelsea \& Westminster NHS Foundation Trust.
There is limited understanding of the causal pathways that lead from the intrauterine environment to later-life obesity and adverse metabolic health, and the neonatal indices or biomarkers that are most predictive of risk. In 5- to 9-y-old children, waist circumference, an index of abdominal adiposity, is the strongest predictor of type-2 diabetes (10). In adults, abdominal obesity and elevated intrahepatocellular lipid (IHCL) have the highest predictive power for the metabolic complications of obesity (11). We postulated that adverse offspring outcome in relation to maternal overweight and obesity may be brought about by alterations to infant body composition established in utero, which are subsequently amplified by diet and other family and external factors. If this is the case, we would expect to see clear relationships between maternal BMI and newborn phenotype. In this study, we tested the hypothesis that infant adiposity and IHCL are modulated by maternal BMI.

\section{METHODS}

This study was conducted as part of a wider program of research investigating the determinants of newborn body composition. Approval was received from the UK National Research Ethics Service. Healthy, full-term infants were recruited from the postnatal wards of Chelsea \& Westminster Hospital, London, UK, following written, informed parental consent. Maternal race classification was defined and assigned by the research team and confirmed by the participant.

Infant body composition and hepatic spectroscopy. Whole body MR imaging was conducted at the Medical Research Council Clinical Sciences Centre of Imperial College London, in accordance with our well-established protocol as previously described (12). Briefly, following a systematic metal check and a feed, infants were scanned in natural sleep. They were swaddled, protected from the noise generated by the scanner with ear plugs and muffs (Natus, CA), positioned on a mobile platform in a supine position and monitored with continuous pulse oximetry and electrocardiography for the duration of the scanning, which was approximately $15 \mathrm{~min}$. $\mathrm{T}_{1}$-weighted rapid spin echo images were acquired using a $\mathrm{Q}$ body coil on a $1.5 \mathrm{~T}$ or 3.0 T Philips Achieva scanner. Proton MR spectra were acquired from the right lobe of the liver using a PRESS sequence (TR $1500 \mathrm{~ms}$, TE $135 \mathrm{~ms}, 128$ averages) without water suppression. All spectra were analyzed in the time domain as previously described by a single investigator (E.L.T.) using AMARES software (13) and blind to maternal BMI. IHCL values were adjusted for $T_{1}$ and $T_{2}$ effects. Hepatic water was used as an internal standard, and results were expressed as IHCL $\mathrm{CH}_{2}$ /water ratio. MR images were analyzed independently of the investigators, blind to subject identity and maternal BMI, by VardisGroup (London, UK, www.vardisgroup.com), utilizing an image segmentation program (SliceOmatic, Tomovision, Montreal, Canada). Each of six

Abbreviations: AT, adipose tissue; IHCL, intrahepatocellular lipid; PI, ponderal index 
adipose tissue (AT) compartments (superficial s.c. abdominal, superficial s.c. nonabdominal, deep s.c. abdominal, deep s.c. nonabdominal, internal abdominal, and internal nonabdominal) was quantified individually as previously described (14). The three abdominal compartments and three nonabdominal compartments were summated to derive abdominal and nonabdominal AT content, respectively; all six compartments were summated to derive total AT content. The coefficient of variation for these measurements is <3\% (15).

Mother and infant anthropometry. Maternal weight and height were obtained from her medical record at booking. Infant body weight $(\mathrm{g})$ was measured at the time of scanning using a calibrated electronic scale (Marsden Professional Baby Scale; Precision $\pm 2 \mathrm{~g}$ ). A measuring board with a sliding footboard was used for measuring crown-heel length $(\mathrm{cm})$ (Rollametre: Raven Equipment Ltd., Dunmow, Essex, UK). The infants head was held against the headboard, while the legs were extended and the sliding footboard brought into contact with the infant's heels. Head circumference was measured with a nonextendable plastic metric band (Child Growth Foundation). Measurements were taken midway between the eyebrows and the hairline at the front and round the occipital prominence at the back. Ponderal index (PI) was calculated using Rohrer's formula $=100 \times$ body weight $(\mathrm{g}) /$ length $(\mathrm{cm})^{3}(16)$.

Data analysis. Analysis was performed using SPSS version 17 and Stata version 11. Statistical significance was defined as $p<0.05$. We calculated the correlation coefficient for maternal BMI with the variables total AT, abdominal AT, nonabdominal AT, the ratio abdominal AT/nonabdominal AT, infant weight, IHCL, infant length at time of scanning, and PI. Pearson correlation was used for normally distributed variables and Spearman correlation for nonnormally distributed variables. For each of these variables, differences between boys and girls were tested for significance using the $t$ test for normally distributed variables; otherwise the Mann Whitney U test was used. Multiple regression analysis was performed to assess all relationships between maternal BMI, adiposity, and IHCL adjusting for infant weight, gender, and postnatal age where associations were significant. We investigated whether there was an interaction between gender and maternal BMI and assessed the effects of maternal race and diabetes. To check for violation of regression assumptions, standardized residuals were assessed for normality. Where necessary, transformations of variables were used to improve the normality of residuals. Adjusted results were illustrated graphically by plotting the observed values standardized for the regression covariates against maternal BMI.

\section{RESULTS}

We studied 105 mother-infant pairs (54 boys and 51 girls) at mean (range) postnatal age of 11.7 (1-28) d. Sixty-eight babies were exclusively breastfed, 13 predominantly breastfed, 3 exclusively formula-fed, 1 predominantly formula-fed, and 10 were approximately half breastfed and half formulafed. Information about feeding was not available for 10 babies. As there were few exclusively or predominantly formulafed babies, feeding was not included as a covariate in the multivariable models. We acquired IHCL spectra in 44 boys and 45 girls and body composition data in 52 boys and 50 girls; incomplete datasets arose where a baby did not remain asleep for sufficiently long. Maternal BMI ranged from 16.7 to
$36.0 ; 12$ mothers were well-controlled diabetics (10 gestational; one type 2; and one type 1). There were five mothers in the World Health Organization BMI $\left(\mathrm{kg} / \mathrm{m}^{2}\right)$ category underweight $(<18.5), 69$ normal weight (18.5-24.9), 23 overweight (25-29.9), and eight obese ( $\geq 30)$. There were 13 south-Asian, two African-American, 75 Caucasian, five African, and 10 mixed race mothers.

IHCL data were skewed and included 0 values. Therefore, a constant (0.034), calculated to minimize skew, was added to each value and a $\log _{\mathrm{e}}$ transform taken. We denote $\log _{\mathrm{e}}(\mathrm{IHCL}+0.034)$ by $\operatorname{lnIHCL}$. Univariable analysis revealed significant correlations between maternal BMI and total AT $(r=0.22, p=0.02)$, abdominal AT $(r=0.28, p=$ $0.005)$, nonabdominal AT $(r=0.21, p=0.04)$, and IHCL (Spearman $\rho=0.23, p=0.03$ ) but not between maternal BMI and the ratio abdominal AT/nonabdominal AT $(r=0.16, p=$ $0.10)$, infant weight $(r=0.05, p=0.59)$, length $(r=0.08$, $p=0.43)$, and PI $(r=0.02, p=0.82)$. Boys and girls were comparable in weight, length, PI, IHCL, and maternal BMI. Girls were significantly more adipose than boys, but there was no difference in the ratio abdominal AT/nonabdominal AT (Table 1).

The multivariable analysis (Table 2) confirmed evidence of associations between maternal BMI and infant AT compartments, after adjusting for infant sex and weight. With each incremental unit of maternal BMI, there was an increase in infant total AT of $8 \mathrm{~mL}(95 \% \mathrm{CI}, 0.9-14.0 ; p=0.03$ ), abdominal AT $2 \mathrm{~mL}$ (95\% CI, 0.7-4.0; $p=0.005)$, and nonabdominal AT $5 \mathrm{~mL}$ (95\% CI, $-0.09-11.0 ; p=0.054)$. Infant weight, sex, and maternal BMI accounted for around half the variance in infant total adiposity, abdominal AT, and nonabdominal AT (adjusted $R^{2}=0.57,0.49$, and 0.57 , respectively). Figure 1 shows total AT against maternal BMI, adjusting for infant weight and sex. Figure 2 shows this relationship for the abdominal and nonabdominal compartments. Adjustment for postnatal age did not change the regression coefficients or the conclusions drawn, and in view of collinearity with infant weight, postnatal age was therefore excluded from the final model.

There was a strong correlation between IHCL and postnatal age (Spearman $\rho=0.42, p<0.0001$ ) but not with infant weight $(p=0.583)$. There was a significant positive association $(p=0.029)$ between maternal BMI and IHCL having

Table 1. Population characteristics by infant gender; values are mean (SD) unless otherwise indicated

\begin{tabular}{|c|c|c|c|c|}
\hline Variable & Total $(n=105)$ & Boys $(n=54)$ & Girls $(n=51)$ & $p$ value for difference \\
\hline Maternal BMI $\left(\mathrm{kg} / \mathrm{m}^{2}\right)$ & $23.6(4.2)$ & $23.3(3.9)$ & $23.9(4.4)$ & 0.45 \\
\hline Total AT $(\mathrm{mL})^{*}$ & 787 (219) & $741(205)$ & $835(225)$ & 0.03 \\
\hline Abdominal AT $(\mathrm{mL})^{*}$ & $149(45)$ & $140(40)$ & $160(48)$ & 0.02 \\
\hline Nonabdominal $(\mathrm{mL})^{*}$ & $638(178)$ & $602(170)$ & $675(180)$ & 0.04 \\
\hline Abdominal:nonabdominal AT & $0.24(0.03)$ & $0.23(0.03)$ & $0.24(0.03)$ & 0.62 \\
\hline $\mathrm{IHCL} \dagger+$ & $0.41(0.05-0.91)$ & $0.55(0.08-0.99)$ & $0.33(0.00-0.63)$ & 0.16 \\
\hline Infant weight $(\mathrm{kg})$ & $3.46(0.48)$ & $3.46(0.51)$ & $3.47(0.45)$ & 0.89 \\
\hline Infant weight gain from birth to scanning $(\mathrm{kg})$ & $0.08(0.30)$ & $0.11(0.32)$ & $0.06(0.27)$ & 0.40 \\
\hline Length $(\mathrm{cm})$ & $52.6(2.67)$ & $52.7(2.60)$ & $52.4(2.77)$ & 0.56 \\
\hline PI $\left(\mathrm{g} / \mathrm{cm}^{3}\right)$ & $23.9(2.67)$ & $23.6(2.51)$ & $24.3(2.81)$ & 0.21 \\
\hline
\end{tabular}

* Boys, $n=52$; girls, $n=50$.

$\dagger$ Boys, $n=44$; girls, $n=45$.

$\$$ Median (interquartile range) and $p$ value from Mann-Whitney $U$ test. 
Table 2. Multiple regression results for infant adiposity

\begin{tabular}{cccc}
\hline & $\begin{array}{c}\text { Regression } \\
\text { coefficient }(\beta)^{*}\end{array}$ & $p$ & $\begin{array}{c}95 \% \text { confidence } \\
\text { interval }\end{array}$ \\
\hline Total AT (mL) adjusted & & & \\
$R^{2}=0.57$ & & & \\
Maternal BMI $\left(\mathrm{kg} / \mathrm{m}^{2}\right)$ & 8 & 0.027 & $0.9-14$ \\
Sex (baseline $=$ male) & 85 & 0.003 & $29-141$ \\
Infant weight $(\mathrm{kg})$ & 339 & $<0.001$ & $277-401$ \\
Abdominal AT $(\mathrm{mL})$ & & & \\
adjusted $R^{2}=0.49$ & & & \\
Maternal BMI $\left(\mathrm{kg} / \mathrm{m}^{2}\right)$ & 2 & 0.005 & $0.7-4$ \\
Sex (baseline $=$ male) & 19 & 0.004 & $6-32$ \\
Infant weight $(\mathrm{kg})$ & 61 & $<0.001$ & $47-75$ \\
Nonabdominal AT $(\mathrm{mL})$ & & & \\
adjusted $R^{2}=0.57$ & & & \\
Maternal BMI $\left(\mathrm{kg} / \mathrm{m}^{2}\right)$ & 5 & 0.054 & $-0.09-11$ \\
Sex (baseline $=\mathrm{male})$ & 66 & 0.005 & $20-112$ \\
Infant weight $(\mathrm{kg})$ & 278 & $<0.001$ & $227-329$ \\
IHCL adjusted $R^{2}=0.23$ & & & \\
Maternal BMI $\left(\mathrm{kg} / \mathrm{m}^{2}\right)$ & $8.6 \%$ & 0.025 & $1.1-16.8$ \\
Sex (baseline $=\mathrm{male})$ & $-40.7 \%$ & 0.09 & $-67.5-8$ \\
Age at scan $(\mathrm{d})$ & $12.2 \%$ & $<0.001$ & $6.6-18.2$ \\
\hline
\end{tabular}

* Percent change for IHCL outcome.

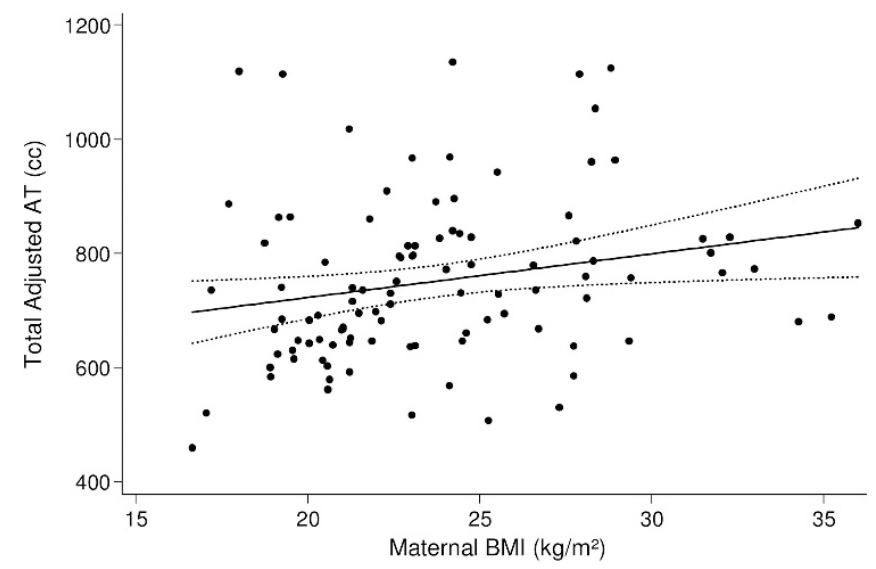

Figure 1. Total AT adjusted for infant sex and weight against maternal BMI, with fitted regression line (solid) and 95\% CI for the mean (dotted).

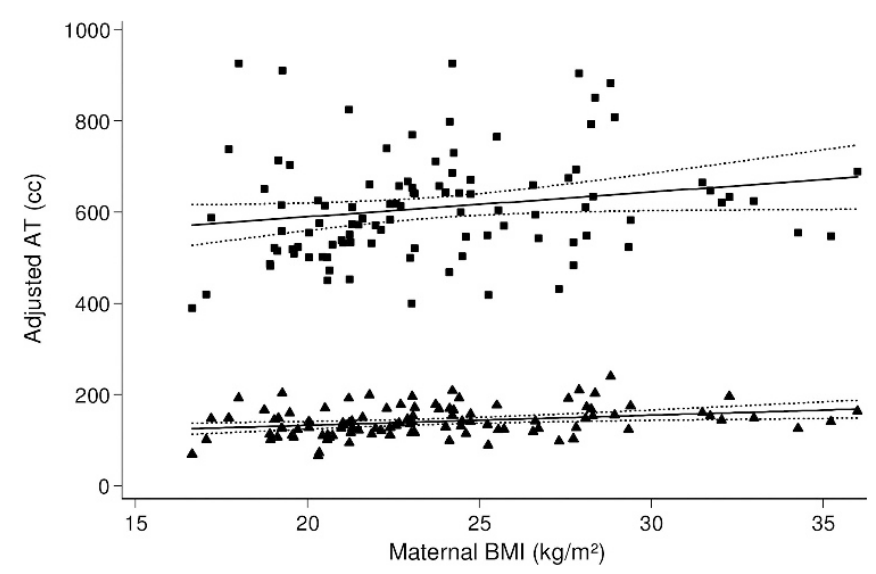

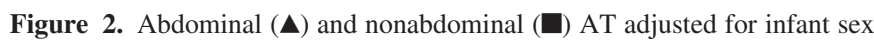
and weight against maternal BMI, with fitted regression lines (solid) and 95\% CIs for the means (dotted).

adjusted for sex and postnatal age (Table 2). For each unit increase in maternal BMI, InIHCL increased by 0.083 , corresponding to (after exponentiation to back-transform

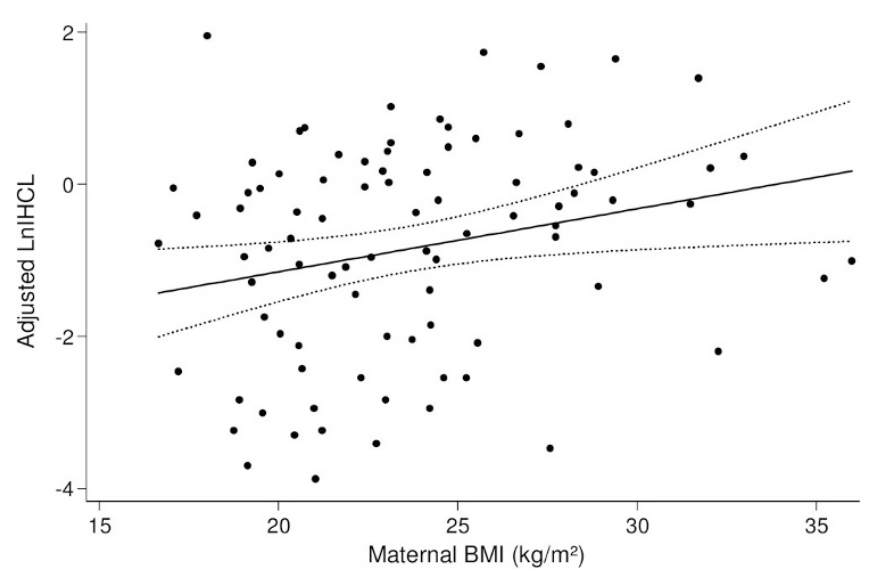

Figure 3. Ln (IHCL) adjusted for infant sex and postnatal age against maternal BMI, with fitted regression line (solid) and 95\% CI for the mean (dotted); IHCL is expressed as $\mathrm{CH}_{2} /$ water ratio and has no units.

the variable) an increase in IHCL of $8.6 \%$ (95\% CI, 1.1$16.8 ; p=0.03$ ). This percentage change is a slightly conservative approximation because of the addition of the constant in the transformation. Figure 3 shows InIHCL against maternal BMI adjusting for sex and postnatal age.

The data did not indicate a relationship between maternal BMI and the ratio abdominal/nonabdominal AT, either in the univariable analysis $(p=0.10)$ or after adjusting for sex and weight $(p=0.10)$. There was no significant evidence of an interaction between maternal BMI and infant sex, or of an effect of maternal race or diabetes on total, abdominal, and nonabdominal AT or lnIHCL.

\section{DISCUSSION}

Using a direct method of assessment, we have shown that infant adiposity, in particular abdominal AT, and IHCL increase across the normal range of maternal BMI. AT partitioning, the relative distribution between compartments does not appear to be affected. Previous studies aiming to elucidate the relationship between maternal BMI and offspring adiposity have used indirect methods for the assessment of infant body composition and have focused on maternal overweight and obesity rather than the full range of BMI. In the main, these earlier studies have shown higher total body fat in infants born to overweight and obese mothers $(17,18)$ but have not addressed AT distribution or IHCL.

To our best knowledge, we are the only group to have previously published data on infant IHCL measured noninvasively by proton MR spectroscopy (13). In nonhuman primates, maternal obesity induces epigenetic changes in genes regulating energy metabolism in offspring liver resulting in a 3 -fold increase in liver lipid and the histological features of nonalcoholic fatty liver disease (19). In human adults, IHCL and abdominal adiposity are strongly correlated with insulin resistance and the metabolic syndrome. An increase in adiposity or hepatic lipid established in early life may be the initiating events increasing offspring vulnerability to subsequent obesogenic influences and life-style choices within the family and wider society. Demonstration that the effects we have described persist would strengthen this inference and is 
therefore a clear focus for further investigation. We noted infant IHCL to be strongly correlated with postnatal age. However, these data are cross sectional and do not reflect true change with time. A longitudinal study evaluating each baby serially is needed to assess the true effect of postnatal age on IHCL.

A reasonable consideration is whether our data reflect race or other intrauterine influences rather than maternal BMI. We have previously shown clear differences in adiposity between Caucasians and south-Asian Indian babies (14). In this study, we found no evidence of an effect of maternal race, but we acknowledge that distribution across racial groups was unbalanced and such an effect cannot be excluded with certainty. Large population studies show that there is a positive relationship between maternal BMI and infant weight. The increase in absolute AT content with increasing maternal BMI in our study was not accompanied by an increase in infant weight. This may reflect a lack of study power but would also indicate that AT content is a more sensitive measure of the influence of maternal BMI. In addition, infant lean body mass may be reduced with increasing maternal BMI. In animal models, maternal obesity down-regulates myogenesis and diverts mesenchymal stem cell differentiation toward adipogenesis in fetal skeletal muscle (20). Epidemiological studies have identified a U-shaped association between birth weight and later-life abdominal obesity $(21,22)$. There is also evidence for both a U-shaped (23) and an inverse association (24) between birth weight and type- 2 diabetes. The association between birth weight and later BMI and overweight in children and young adults is linear and positive in some studies and J- or U-shaped in others (25). A U-shaped association between maternal BMI and infant adiposity is also biologically plausible. Our data did not show significant departures from linearity although the scant number of women in the underweight and overweight/ obese groups limited our power to detect a more complex association.

The majority of women in our study were in the "healthy" BMI category, indicating that infant body composition is very sensitive to maternal BMI. The causal intrauterine perturbations, for which BMI is a proxy, are not known with certainty, although hyperglycemia is undoubtedly the prime candidate. Glucose and amino acids represent the principal feto-placental nutrient substrates. Glucose is transferred by facilitated diffusion along a positive maternal-fetal gradient. In contrast, there is active placental transfer of amino acids against a gradient. Several factors affect placental amino acid delivery, including placental surface area, utero-placental blood flow, and maternal amino acid concentrations. Impaired placental function has a recognized association with maternal obesity (26), and impaired amino acid delivery would be reflected in decreased infant lean body mass. Hillier et al. (27) evaluated childhood obesity across the full range of hyperglycemia in pregnancy. Offspring of women with a normal glucose tolerance test, but with values in the upper quartile, had an OR of 1.22 (95\% CI, 1.03-1.45) for obesity by age 5 to $7 \mathrm{y}$, offering support for an effect of increased fetal glucose delivery. A continuous relationship has been shown between maternal glycemia less severe than would occur in overt diabetes and indirect mea- sures of both infant adiposity and hyperinsulinemia (cord blood C-peptide) (21). In our study, maternal diabetes was not a significant covariate in the regression model although the number was small. Disentangling the contributions of diabetes from maternal glycemia is clearly needed.

To date, clinical advice to expectant mothers has largely focused on pregnancy weight gain rather than optimal prepregnancy BMI. Pregnancy weight gain is associated with greater neonatal fat mass, but only weakly associated with offspring fat mass at $6 \mathrm{y}$ (28), suggesting that mechanisms other than an effect on infant total adiposity may be involved. The US Institute of Medicine has recently published revised guidelines for pregnancy weight gain (29) although the strength of much of the contributory evidence is moderate or weak (30).

There are good reasons to suggest that prepregnancy BMI, rather than pregnancy weight gain, may be more predictive of offspring outcome. Pregnancy weight gain is made up of extracellular fluid expansion, maternal AT deposition, as well as the infant and other products of conception. Obese women also gain less weight than lean women during pregnancy, and hypertension, preeclampsia, Caesarean section, and gestational diabetes have stronger and more consistent associations with prepregnancy BMI, than with pregnancy weight gain $(31,32)$. A limitation of our study was that we were unable to assess pregnancy weight gain in our study but resolving this uncertainty is essential if women are to be provided with sound advice.

In summary, our data suggest several distinct biological pathways by which increasing maternal BMI might initiate an adverse health trajectory in offspring and may help to explain the epidemiological associations with metabolic complications and obesity in later life. We have shown a continuous effect across the normal range of maternal BMI on infant whole body and abdominal adiposity and IHCL. In other age groups, these are markers of increased risk of impaired insulin sensitivity. Whether this is the case in the newborn is unknown. The concurrent lack of association between maternal BMI and infant weight in this cohort of healthy mothers and babies suggests the additional possibility of a reduction in offspring lean body mass. Our observations require confirmation with the inclusion of mothers from either end of the BMI spectrum, ideally using prepregnancy, rather than booking weight. Further key questions that must be addressed are whether these putative biomarkers track through infancy and childhood, their predictive value, and the extent to which they are modified by diet and postneonatal environmental influences. Current public health stratagems remain largely targeted on overweight and obesity. This approach detracts from the need to identify the range of maternal prepregnancy BMI that is associated with the most favorable long-term infant outcome. We suggest that the prevention of obesity and associated metabolic complications should begin during intrauterine life.

Acknowledgments. We thank Vimal Vasu, MBBS (East Kent Hospitals University NHS Foundation Trust), Karen Logan, MBBS (Imperial College London), Tracey Harrington, 
$\mathrm{PhD}$ (Dublin City University), and Sabita Uthaya, MD (Chelsea \& Westminster NHS Foundation Trust) for their help with patient recruitment, Giuliana Durighel, MSc (Imaging Sciences) and Julie Fitzpatrick (Imperial College London) for their skill in acquiring magnetic resonance images and hepatic spectra. None of the above named contributors received additional compensation for their involvement.

\section{REFERENCES}

1. Kanagalingam MG, Forouhi NG, Greer IA, Sattar N 2005 Changes in booking body mass index over a decade: retrospective analysis from a Glasgow Maternity Hospital. BJOG 112:1431-1433

2. Weiss R, Dziura J, Burgert TS, Tamborlane WV, Taksali SE, Yeckel CW, Allen K, Lopes M, Savoye M, Morrison J, Sherwin RS, Caprio S 2004 Obesity and the metabolic syndrome in children and adolescents. N Engl J Med 350:2362-2374

3. The Confidential Enquiry into Maternal and Child Health (CEMACH) 2007 Saving mothers' lives: reviewing maternal deaths to make motherhood safer-2003-2005. The Seventh Report of the Confidential Enquiries into Maternal Deaths in the United Kingdom. CEMACH, London. Available at: http://www.cemach.org.uk/ getattachment/26dae364-1fc9-4a29-a6cb-afb3f251f8f7/Saving-Mothers'-Lives2003-2005-(Full-report).aspx. Accessed January 23, 2011

4. Boney CM, Verma A, Tucker R, Vohr BR 2005 Metabolic syndrome in childhood: association with birth weight, maternal obesity, and gestational diabetes mellitus. Pediatrics 115:e290-e296

5. Catalano PM, Farrell K, Thomas A, Huston-Presley L, Mencin P, Hauguel de Mouzon S, Amini SB 2009 Perinatal risk factors for childhood obesity and metabolic dysregulation. Am J Clin Nutr 90:1303-1313

6. Whitaker RC 2004 Predicting preschooler obesity at birth: the role of maternal obesity in early pregnancy. Pediatrics 114:e29-e36

7. Baker JL, Michaelsen KF, Sorensen TI, Rasmussen KM 2007 High prepregnan body mass index is associated with early termination of full and any breastfeeding in Danish women. Am J Clin Nutr 86:404-411

8. Rasmussen KM, Kjolhede CL 2004 Prepregnant overweight and obesity diminish the prolactin response to suckling in the first week postpartum. Pediatrics 113:e465e471

9. Harder T, Bergmann R, Kallischnigg G, Plagemann A 2005 Duration of breastfeeding and risk of overweight: a meta-analysis. Am J Epidemiol 162:397-403

10. Franks PW, Hanson RL, Knowler WC, Moffett C, Enos G, Infante AM, Krakoff J, Looker HC 2007 Childhood predictors of young-onset type 2 diabetes. Diabetes $56: 2964-2972$

11. Fabbrini E, Magkos F, Mohammed BS, Pietka T, Abumrad NA, Patterson BW, Okunade A, Klein S 2009 Intrahepatic fat, not visceral fat, is linked with metabolic complications of obesity. Proc Natl Acad Sci U S A 106:15430-15435

12. Harrington TA, Thomas EL, Frost G, Modi N, Bell JD 2004 Distribution of adipose tissue in the newborn. Pediatr Res 55:437-441

13. Thomas EL, Uthaya S, Vasu V, McCarthy JP, McEwan P, Hamiltion G, Bell JD, Modi N 2008 Neonatal intrahepatocellular lipid. Arch Dis Child Fetal Neonatal Ed 93:F382-F383

14. Modi N, Thomas EL, Uthaya SN, Umranikar S, Bell JD, Yajnik C 2009 Whole body magnetic resonance imaging of healthy newborn infants demonstrates increased central adiposity in Asian Indians. Pediatr Res 65:584-587

15. Thomas EL, Hamilton G, Patel N, O'Dwyer R, Doré CJ, Goldin RD, Bell JD, Taylor-Robinson SD 2005 Hepatic triglyceride content and its relation to body adiposity: a magnetic resonance imaging and proton magnetic resonance spectroscopy study. Gut 54:122-127

16. Rohrer R 1921 [The index of corpulence as a measure of nutritional status]. Munch Med Wochenschr 68:580-583

17. Hull HR, Dinger MK, Knehans AW, Thompson DM, Fields DA 2008 Impact of maternal body mass index on neonate birthweight and body composition. Am J Obstet Gynecol 198:416.e1-416.e6

18. Sewell MF, Huston-Presley L, Super DM, Catalano P 2006 Increased neonatal fat mass, not lean body mass, is associated with maternal obesity. Am J Obstet Gynecol 195:1100-1103

19. Aagaard-Tillery KM, Grove K, Bishop J, Ke X, Fu Q, McKnight R, Lane RH 2008 Developmental origins of disease and determinants of chromatin structure: maternal diet modifies the primate fetal epigenome. J Mol Endocrinol 41:91-102

20. Du M, Yan X, Tong JF, Zhao J, Zhu MJ 2010 Maternal obesity, inflammation, and fetal skeletal muscle development. Biol Reprod 82:4-12

21. HAPO Study Cooperative Research Group 2009 Hyperglycemia and Adverse Pregnancy Outcome (HAPO) Study: associations with neonatal anthropometrics. Diabetes 58:453-459

22. Tian JY, Cheng Q, Song XM, Li G, Jiang GX, Gu YY, Luo M 2006 Birth weight and risk of type 2 diabetes, abdominal obesity and hypertension among Chinese adults. Eur J Endocrinol 155:601-607

23. Whincup PH, Kaye SJ, Owen CG, Huxley R, Cook DG, Anazawa S, Barrett-Connor E, Bhargava SK, Birgisdottir BE, Carlsson S, de Rooij SR, Dyck RF, Eriksson JG, Falkner B, Fall C, Forsén T, Grill V, Gudnason V, Hulman S, Hyppönen E, Jeffreys M, Lawlor DA, Leon DA, Minami J, Mishra G, Osmond C, Power C, Rich-Edwards JW, Roseboom TJ, Sachdev HS, Syddall H, Thorsdottir I, Vanhala M, Wadsworth M, Yarbrough DE 2008 Birth weight and risk of type 2 diabetes: a systematic review. JAMA 300:2886-2897

24. Harder T, Rodekamp E, Schellong K, Dudenhausen JW, Plagemann A 2007 Birth weight and subsequent risk of type 2 diabetes: a meta-analysis. Am J Epidemiol $165: 849-857$

25. Rogers I 2003 The influence of birthweight and intrauterine environment on adiposity and fat distribution in later life. Int J Obes Relat Metab Disord 27:755-777

26. Farley D, Tejero ME, Comuzzie AG, Higgins PB, Cox L, Werner SL, Jenkins SL, Li C, Choi J, Dick EJ Jr, Hubbard GB, Frost P, Dudley DJ, Ballesteros B, Wu G, Nathanielsz PW, Schlabritz-Loutsevitch NE 2009 Feto-placental adaptations to maternal obesity in the baboon. Placenta 30:752-760

27. Hillier TA, Pedula KL, Schmidt MM, Mullen JA, Charles MA, Pettitt DJ 2007 Childhood obesity and metabolic imprinting: the ongoing effects of maternal hyperglycemia. Diabetes Care 30:2287-2292

28. Crozier SR, Inskip HM, Godfrey KM, Cooper C, Harvey NC, Cole ZA, Robinson SM; Southampton Women's Survey Study Group 2010 Weight gain in pregnancy and childhood body composition: findings from the Southampton Women's Survey. Am J Clin Nutr 91:1745-1751

29. Rasmussen KM, Yaktine AL 2009 Weight Gain During Pregnancy: Reexamining the Guidelines. The National Academies Press, Washington, D.C. Available at: http://books.nap.edu/openbook.php?record_id=12584. Accessed January 23, 2011

30. Siega-Riz AM, Viswanathan M, Moos MK, Deierlein A, Mumford S, Knaack J, Thieda P, Lux LJ, Lohr KN 2009 A systematic review of outcomes of maternal weight gain according to the Institute of Medicine recommendations: birthweight, fetal growth, and postpartum weight retention. Am J Obstet Gynecol 201:339.e1339.e14

31. Jensen DM, Damm P, Sørensen B, Mølsted-Pedersen L, Westergaard JG, Ovesen P, Beck-Nielsen H 2003 Pregnancy outcome and prepregnancy body mass index in 2459 glucose-tolerant Danish women. Am J Obstet Gynecol 189:239-244

32. Nohr EA, Vaeth M, Baker JL, Sorensen T, Olsen J, Rasmussen KM 2008 Combined associations of prepregnancy body mass index and gestational weight gain with the outcome of pregnancy. Am J Clin Nutr 87:1750-1759 